Proceedings of XIX International Scientific Conference "New Technologies and Achievements in Metallurgy, Material Engineering, Production Engineering and Physics", Częstochowa, Poland, June 7-8, 2018

\title{
The Microstructural Changes due to the Heating Treatment of Magnetic Amorphous $\mathrm{Fe}_{81}(\mathrm{PtRh})_{5} \mathrm{Zr}_{7} \mathrm{Nb}_{1} \mathrm{Cu}_{1} \mathrm{~B}_{5}$ Alloy
}

\author{
J. GONDRO*
}

Institute of Physics, Częstochowa University of Technology, al. Armii Krajowej 19, 42-200 Częstochowa, Poland

\begin{abstract}
The chemical components and carefully selected thermal treatment of the material sample give the possibility to obtain a alloy with appropriate magnetic properties. The paper presents the results of the microstructure and magnetic properties of the $\mathrm{Fe}_{81}(\mathrm{PtRh})_{5} \mathrm{Zr}_{7} \mathrm{Nb}_{1} \mathrm{Cu}_{1} \mathrm{~B}_{5}$ amorphous alloy in the state after solidification and after thermal treatment. Each sample was annealed at four steps, 15 min at every temperature, starting from $600 \mathrm{~K}$ up to $+800 \mathrm{~K}$ depending on type of alloy. The alloys were investigated in as-quenched state, obtained in the form of thin ribbons with approximate dimensions: width $3 \mathrm{~mm}$ and thickness $20 \mu \mathrm{m}$. The ribbons were obtained from high purity elements by melting with the use of arc. The production process was carried out in a protective atmosphere of an inert gas $(\mathrm{Ar})$. Structure and microstructure were investigated using the Mössbauer spectroscopy and X-ray diffractometry. The Mössbauer spectra were recorded using a POLON Mössbauer spectrometer, equipped with a ${ }^{57} \mathrm{Co}(\mathrm{Rh})$ source with $50 \mathrm{mCi}$ activity, at room temperature. The Mössbauer transmission spectra were analyzed using the "NORMOS" software. X-ray diffraction of the investigated strips was carried out using a Brucker Advance D8 diffractometer. From X-ray and the Mössbauer spectroscopy investigations, it has been stated that the asquenched samples were fully amorphous.
\end{abstract}

DOI: 10.12693/APhysPolA.135.183

PACS/topics: 75.47.Np, 75.50.Bb, 75.50.Kj, 75.90.+w

\section{Introduction}

The rapid development of science and technology caused a significant increase in interest in electrotechnical materials exhibiting good soft magnetic properties, both with amorphous and nanocrystalline structures. Such materials are obtained in the process of rapid solidification of the liquid alloy. This technique gives the possibility of obtaining tapes with a thickness of several dozen micrometers, tubes, plates or bars with a thickness of a few millimeters [1-4]. One of the many methods of obtaining classical crystalline alloys is the method consisting in rolling ingots and then subjecting them to heat treatment.

Providing a large portion of energy defined as the activation energy of the crystallization process to the amorphous alloy leads to the initiation of nucleation seeds in its entire volume and in the next stage to their growth and the formation of nanometric crystalline grains [5-9]. Nanocrystalline alloys can be obtained through a controlled process of heating up amorphous materials $[10,11]$.

A wide range of applications of functional materials with amorphous structure resulted in a significant increase in their use, among others in electric motors or microgenerators, as well as in the automotive industry [12]. Unfortunately, one of the limitations of the applicability of platinum containing alloys with rhodium is their high price.

\footnotetext{
*e-mail: j.gondro@wp.pl
}

In this paper, investigations are presented into the: microstructure and soft magnetic properties occurring in samples of amorphous and crystallized, multicomponent, $\mathrm{Fe}_{81}(\mathrm{PtRh})_{5} \mathrm{Zr}_{7} \mathrm{Nb}_{1} \mathrm{Cu}_{1} \mathrm{~B}_{5}$ alloy.

\section{Experimental procedure}

Ingots of studied alloy with composition $\mathrm{Fe}_{81}(\mathrm{PtRh})_{5} \mathrm{Zr}_{7} \mathrm{Nb}_{1} \mathrm{Cu}_{1} \mathrm{~B}_{5}$ were obtained by melting the high-purity components in the electric arc. The $30 \mathrm{wt} \%$ of platinum and $20 \mathrm{wt} \%$ of rhodium was used in the investigated alloy. Using the method of rapid cooling of liquid metal on a single rotating copper cylinder, amorphous tapes with a width of $3 \mathrm{~mm}$ and a thickness of $20 \mu \mathrm{m}$ were produced. The entire production process took place in a protective atmosphere of argon. The alloy sample was subjected to a multistage heat treatment. This allowed to avoid the slight difference in the chemical composition of the alloy along the length of the strip during measurements. The conditions of thermal treatment of samples are given in Table I. The heat

TABLE I

Conditions for the multi-stage heat treatment of alloy samples ( + sign means the next stage of heat treatment).

\begin{tabular}{c|c}
\hline \hline Alloy composition & $\begin{array}{c}\text { Heat treatment } \\
\text { temperature/time }\end{array}$ \\
\hline & $+600 \mathrm{~K} / 15 \mathrm{~min}$ \\
& $+670 \mathrm{~K} / 15 \mathrm{~min}$ \\
$\mathrm{Fe}_{81}(\mathrm{PtRh})_{5} \mathrm{Zr}_{7} \mathrm{Nb}_{1} \mathrm{Cu}_{1} \mathrm{~B}_{5}$ & $+720 \mathrm{~K} / 15 \mathrm{~min}$ \\
& $+760 \mathrm{~K} / 15 \mathrm{~min}$ \\
& $+800 \mathrm{~K} / 15 \mathrm{~min}$
\end{tabular}




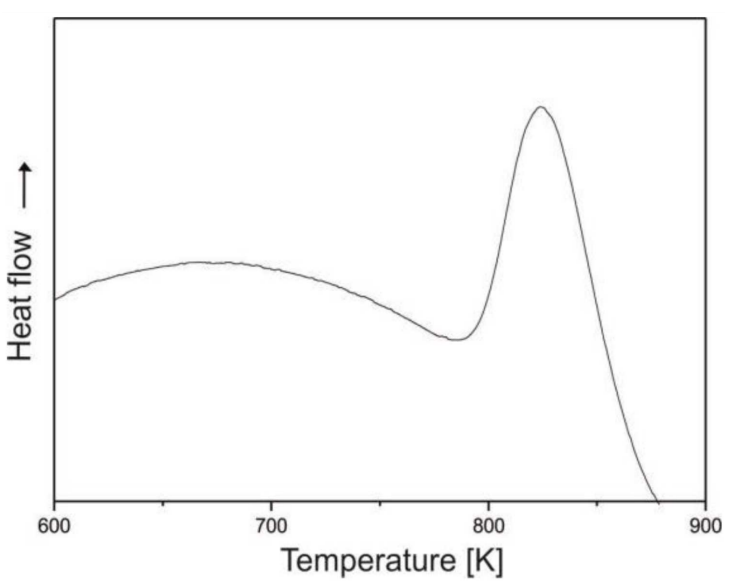

Fig. 1. Isochronal DSC curves recorded at heating rate $10 \mathrm{~K} / \mathrm{min}$ for the amorphous alloy.

treatment was carried out in a vacuum. The thermal stability of the investigated alloys was determined using a differential scanning calorimeter (DSC). DSC measurements for the alloy samples were made on a commercial Netzsch Simultaneous Thermal Analyzer STA409C with a 32-bit controller. Heat flow tests as a function of temperature were carried out at the heating rate of $10 \mathrm{~K} / \mathrm{min}^{-1}$ (shown in Fig. 1).
The microstructure and magnetic properties of the sample were investigated, both in the as-quenched state and after annealing. This was achieved at room temperature by means of a POLON Mössbauer spectrometer, equipped with a ${ }^{57} \mathrm{Co}(\mathrm{Rh})$ source with an activity of $50 \mathrm{mCi}$. The transmission Mössbauer spectra were analysed using NORMOS [13] software. The X-ray examinations were carried out using an X-ray diffractometer (Brucker Advanced D8). Diffractograms were made in the angle range $2 \theta$ ranking from $30^{\circ}$ to $130^{\circ}$ using $0.02^{\circ}$ measuring step and $7 \mathrm{~s}$ measuring time. The measurements were made in the Bragg-Brentano geometry using a semiconductor counter and $\mathrm{Cu} K_{\alpha}$ lamp. The measurements of the magnetic susceptibility were performed on the toroidal-shaped samples using a computerized automatic test setup. A magnetic field of amplitude $0.26 \mathrm{~A} / \mathrm{m}$ and a frequency of $2 \mathrm{kHz}$ was used for this stage.

\section{Results and discussion}

The DSC measurements provide qualitative and quantitative information as a function of time and temperature, transitions in the material that require endothermic or exothermic processes or change in thermal capacity can be measured. The advantages of the DSC method include: easy sample preparation, fast analysis time, and a wide temperature range.
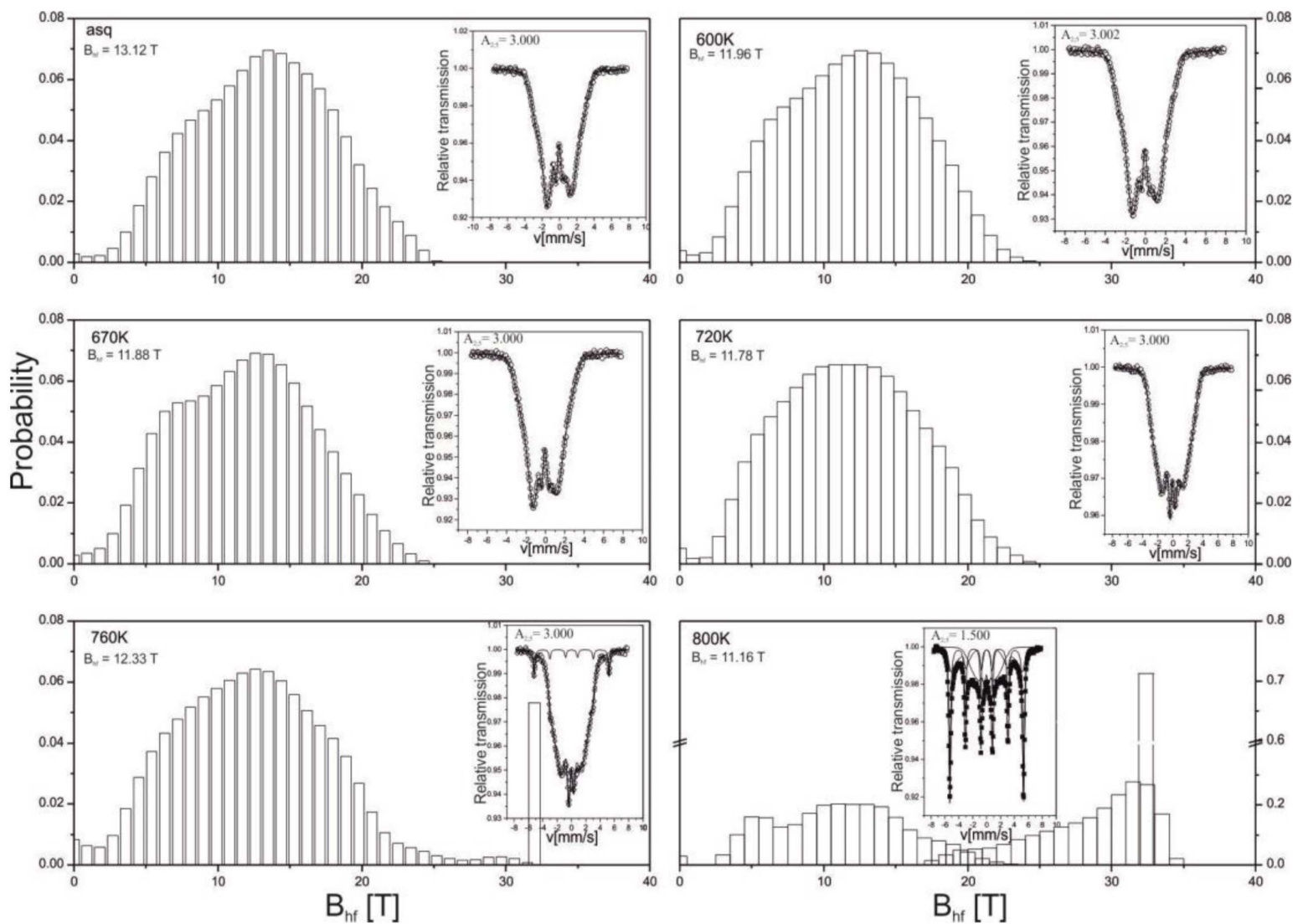

Fig. 2. The corresponding hyperfine field distributions for alloy $\mathrm{Fe}_{81}(\mathrm{PtRh})_{5} \mathrm{Zr}_{7} \mathrm{Nb}_{1} \mathrm{Cu}_{1} \mathrm{~B}_{5}$ and the Mössbauer spectra are in the inset. 
The beginning of the crystallization process is observed at the temperature of $720 \mathrm{~K}$ (Fig. 1), which closely correlates with the results obtained from the Mössbauer spectra and the hyperfine induction field distribution (Fig. 2), associated with the high-field component and the increase in the mean induction value of $\mathrm{B}_{h f}$.

In Fig. $3 \mathrm{X}$-ray diffraction patterns for the as-quenched $\mathrm{Fe}_{81}(\mathrm{PtRh})_{5} \mathrm{Zr}_{7} \mathrm{Nb}_{1} \mathrm{Cu}_{1} \mathrm{~B}_{5}$ ribbons are shown. The patterns with broad maxima located at about $50^{\circ}$ are typical of amorphous materials and this confirms the structural disorder of the investigated alloys. X-ray examinations carried out for alloy samples after heat treatment $600 \mathrm{~K}$ and $670 \mathrm{~K}$ during $15 \mathrm{~min}$ also confirmed their amorphous nature. In Fig. 3 inset, one may observe X-ray diffraction patterns for partially crystallized ribbons with characteristic narrow peak originating from the crystalline phase.

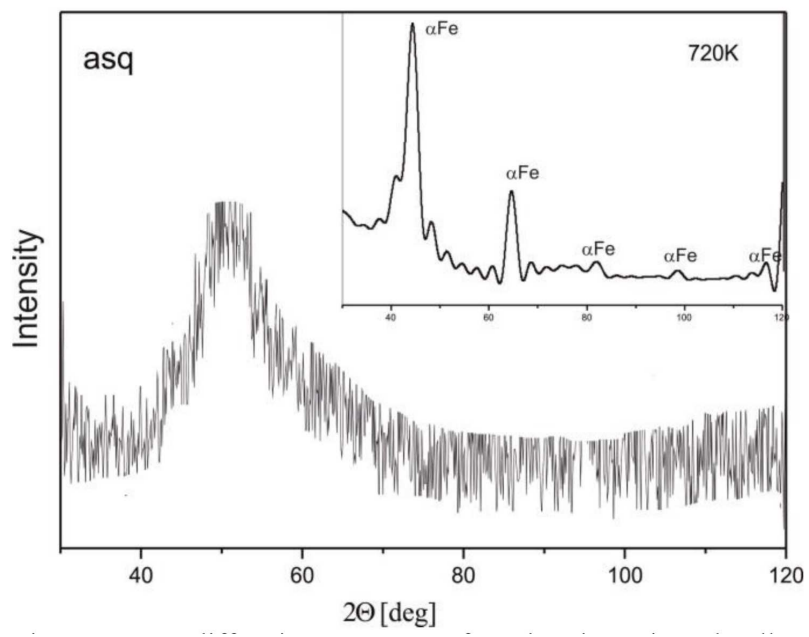

Fig. 3. X-ray diffraction patterns for the investigated alloy $\mathrm{Fe}_{81}(\mathrm{PtRh})_{5} \mathrm{Zr}_{7} \mathrm{Nb}_{1} \mathrm{Cu}_{1} \mathrm{~B}_{5}$ : asq state and after annealing at $720 \mathrm{~K}$ for $15 \mathrm{~min}$.

The emergence of grains of the crystalline phase is also visible for the alloy after heat treatment (from $+720 \mathrm{~K}$ ) in the form of a high-field component expansion. Further heat treatment at temperatures of $760 \mathrm{~K}$ and $800 \mathrm{~K}$ respectively within $15 \mathrm{~min}$ results in a clear increase in the intensity of crystalline phase peaks identified as an $\alpha \mathrm{Fe}$ phase.

The asymmetric shape of the hyperfine field induction distribution indicates the existence of two low- and high- field components, associated with different environments of iron atoms. The Mössbauer spectra for the test alloy samples (included in the inserts) are typical for amorphous ferromagnetic alloys with a high iron content $[14,15]$.

Information about the presence of other elements such as $\mathrm{Zr}$ or $\mathrm{B}$, in the immediate vicinity of the iron atoms can be derived from a high-field component, which can be observed in the higher fields of decomposition of hyperfine field distributions on the iron nuclei. From the analysis of the Mössbauer spectra, it can be stated that the intensity of the second line in the Zeeman sexet for the alloy in the state after solidification and after heat treatment to a temperature of $760 \mathrm{~K}$ in $15 \mathrm{~min}$ is 3,000 , which means that the vector magnetization of the tape is perpendicular to the surface. In the case of an alloy sample heated at $800 \mathrm{~K}$, the intensity of $A_{2.5}$ is 1.5 , indicating that the magnetization vector is aligned parallel to the surface of the tape.

The temperature dependences of the magnetic susceptibility for $\mathrm{Fe}_{81}(\mathrm{PtRh})_{5} \mathrm{Zr}_{7} \mathrm{Nb}_{1} \mathrm{Cu}_{1} \mathrm{~B}_{5}$ are given in Fig. 4, respectively.

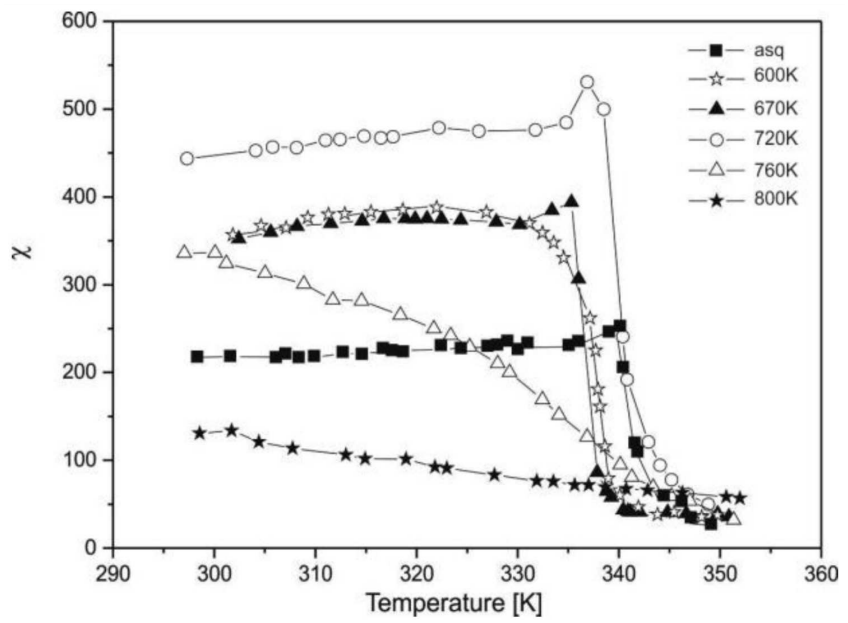

Fig. 4. The magnetic susceptibility curves for the amorphous alloys in the as-quenched state and after annealing.

Figure 4 shows that the heat treatment affects the Curie temperature and magnetic susceptibility of individual samples of the investigated alloy. The ferromagneticparamagnetic transition is observed by the maximum on the curve $\chi(T)$ (so-called the Hopkinson maximum) [16] located near the Curie temperature. A clear maximum on the $\chi(T)$ curve can be observed for the alloy sample in the state after solidification and heat treatment at $670 \mathrm{~K}$ and $720 \mathrm{~K}$ in $15 \mathrm{~min}$.

After processing at $600 \mathrm{~K}$ and $760 \mathrm{~K}$, a wide and stretched to a lower temperature maximum can be observed, while the last treatment at $800 \mathrm{~K}$ gives a completely flat curve. These flat maximum indicates that the sample is not homogeneous. The annealing process leads to an almost double increase in the value of magnetic susceptibility, which is caused by the relaxation of the sample. Further heating of the alloy causes the magnetical hardening of the sample. The susceptibility value is clearly reduced in relation to that observed for the asq sample, and the maximum Hopkinson value is completely fuzzy and flat. The Currie temperature value estimated from magnetic curves (Fig. 4) lies within the limits of $T_{C}=343 \mathrm{~K}$ for the alloy sample in the asq state and decreases for the alloy sample after the heat treatment $670 \mathrm{~K}$ which is $T_{C}=335 \mathrm{~K}$. 


\section{Conclusions}

In conclusion, it may be stated that the multicomponent $\mathrm{Fe}_{81}(\mathrm{PtRh})_{5} \mathrm{Zr}_{7} \mathrm{Nb}_{1} \mathrm{Cu}_{1} \mathrm{~B}_{5}$ alloy in the asquenched state was fully amorphous. The presented X-ray diffraction patterns for $\mathrm{Fe}_{81}(\mathrm{PtRh})_{5} \mathrm{Zr}_{7} \mathrm{Nb}_{1} \mathrm{Cu}_{1} \mathrm{~B}_{5}$ sample after annealing, shows a clear peaks indicating the presence of crystalline phase. The increase in the average magnetic hyperfine induction field for $\mathrm{Fe}_{81}(\mathrm{PtRh})_{5} \mathrm{Zr}_{7} \mathrm{Nb}_{1} \mathrm{Cu}_{1} \mathrm{~B}_{5}$ alloy sample is associated with larger distance between iron atoms and presence in their close neighborhood of other chemical elements. It was found that the samples of the investigated alloys with the lowest values of the hyperfine field induction in ${ }^{57} \mathrm{Fe}$ also exhibit a reduced Curie temperature value compared to the initial state.

\section{References}

[1] S.N. Kane, S. Sarabhai, A. Gupta, L.K. Varga, T. Kulik, J. Magn. Magn. Mater. 215-216, 372 (2000).

[2] M. Al.-Haj, J. Barry, J. Mater. Sci. Lett. 17, 1125 (1998).

[3] K. Błoch, J. Magn. Magn. Mater. 390, 118 (2015).
[4] P. Gębara, Acta Phys. Pol. A 131, 798 (2017).

[5] K. Błoch, M. Nabiałek, M. Dośpiał, S. Garus, Arch. Metall. Mater. 60, 7 (2015).

[6] T. Egami, J. Magn. Magn. Mater. 31-34, 1571 (1983)

[7] Y. Takahara, Mater. Sci. Eng. A 231, 128 (1997).

[8] J. Gondro, J. Świerczek, J. Rzącki, W. Ciurzyńska, J. Olszewski, J. Zbroszczyk, K. Błoch, M. Osyra, A. Łukiewska, J. Magn. Magn. Mater. 341, 100 (2013).

[9] K. Gruszka, J. Rzącki, M. Nabiałek, Rev. Chim. 69, 318 (2018).

[10] J. Gondro, J. Świerczek, K. Błoch, J. Zbroszczyk, W. Ciurzyńska, J. Olszewski, Physica B 445, 37 (2014).

[11] J. Olszewski, Hyperf. Interact. 131, 83 (2000).

[12] G. Kotagiri, S.D. Ramarao, G. Markandeyulu, J. Magn. Magn. Mater. 382, 43 (2015).

[13] R.A. Brand, Nucl. Instrum. Methods Phys. Res. B 28, 398 (1987).

[14] J. Gondro, J. Magn. Magn. Mater. 432, 501 (2017).

[15] M. Nabiałek, Rev. Chim. 69, 148 (2018).

[16] H.W. Kwon, S.W. Shon, J. Magn. 6, 61 (2001). 